\title{
INVESTIGATION OF ROTOR DYNAMICS WITH FLUID FILM INSTABILITIES II
}

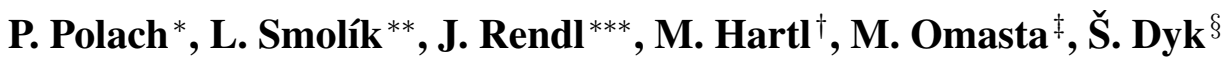

\begin{abstract}
Dynamics of rotating systems involves behaviour and diagnostics of rotating structures. When hydrodynamic journal bearings are used to support a rotor a rotor-bearing system becomes a complex dynamic system that may exhibit serious fluid film instabilities. Understanding of behaviour of a fluid film bearing closely before, during and after the rotor instability origin and growth is the main motivation for a complex research of local and global dynamics of the rotor-bearing system. Deep knowledge of relations between local fluid film dynamics and dynamic response of rotating systems during instabilities can help to improve the design of many modern rotating machines.
\end{abstract}

Keywords: rotor dynamics, fluid film bearings, instabilities, test rig, computational approach.

\section{Introduction}

The paper presents a current state of the experimental and computational investigation in this subject. An experimental test rig is assembled and an example of computational approach is introduced. The aim of the work in progress is to provide a detailed description and a deep explanation of mechanisms of fluid induced instabilities related to nonlinear dynamics of rotor systems.

Dynamics of rotating systems deals with behaviour and diagnostics of rotating structures. When hydrodynamic journal bearings are used to support a rotor a rotor-bearing system becomes a complex dynamic system that may exhibit fluid-induced instabilities. Understanding of behaviour of the journal bearing closely before, during and after the rotor instability origin and growth is the main motivation for a complex research of local and global dynamics of the rotor-bearing system.

During last few years many local aspects regarding fluid film instabilities were introduced (a survey of the literature is given, e.g., in (Polach et al., 2017a). Recent development in numerical methods for nonlinear models and numerical continuation methods allowed studying the oil-induced instabilities and resulting bifurcations even deeper. De Castro et al. (2008) implemented nonlinear hydrodynamic forces and predicted oil whirl/whip for a real vertical power plant and a horizontal test rig. Boyaci et al. (2010) used a numerical continuation method to detect bifurcations of stationary and periodic solutions for a flexible rotor supported by two identical journal bearings. Amamou and Chouchane (2014) discussed the stability issues including hysteresis and jump phenomena of long journal bearings utilizing a nonlinear model and continuation methods.

Dr. Ing. Pavel Polach: New Technologies for the Information Society, European Centre of Excellence, University of West Bohemia, Univerzitní 8; 306 14, Plzeň; CZ, ppolach@ntis.zcu.cz

** Ing. Luboš Smolík: New Technologies for the Information Society, European Centre of Excellence, University of West Bohemia, Univerzitní 8; 306 14, Plzeň; CZ, carlist@ntis.zcu.cz

*** Ing. Jan Rendl: New Technologies for the Information Society, European Centre of Excellence, University of West Bohemia, Univerzitní 8; 306 14, Plzeň; CZ, rendlj@ ntis.zcu.cz

$\dagger$ prof. Ing. Martin Hartl, PhD: Institute of Machine and Industrial Design, Faculty of Mechanical Engineering, Brno University of Technology, Technická 2896/2; 61669 Brno; CZ, hartl@ fme.vutbr.cz

¥ Ing. Milan Omasta, PhD: Institute of Machine and Industrial Design, Faculty of Mechanical Engineering, Brno University of Technology, Technická 2896/2; 61669 Brno; CZ, omasta@ fme.vutbr.cz

$\S \quad$ Ing. Štěpán Dyk, PhD: New Technologies for the Information Society, European Centre of Excellence, University of West Bohemia, Univerzitní 8; 306 14, Plzeň; CZ, sdyk@ntis.zcu.cz 
A typical rotordynamic test rig usually utilizes a set of proximity transducers and accelerometers, which provide orbits of the lateral motion of the shaft centerline. However, this configuration does not allow a deeper investigation of local phenomena in the oil film. For a better understanding of the fluid film behaviour in journal bearings and more accurate prediction of rotordynamic characteristics during instabilities a greater focus should be placed on a local observation of the fluid film using optical methods. A dyed oil and a transparent bearing bushing allow a simple visual inspection of the oil film condition (Fan et al., 2011; Robbersmyr at al., 2014). Lin et al. (2015) introduced a micro particle imaging velocimetry for the visualization of a flow field in the journal bearing. Glavatskikh and Larsson (2006) developed an optic lever technique detecting the light intensity reflected from the target surface for a precise film thickness measurement. The fluid film thickness can also be measured by the laser induced fluorescence technique developed by Nakayama et al. (2003).

\section{An approach to the computational investigation}

A standard equation of motion for rotating bodies is based on the finite element method considering the onedimensional Euler-Bernoulli or Timoshenko beams (Byrtus et al., 2010). The model respects continuous mass of rotating shafts and possible effects of lumped masses such as discs, gear wheels, etc. An equation of motion can be written in the form

$$
\mathbf{M} \cdot \ddot{\mathbf{q}}(t)+\left(\mathbf{B}+\omega_{0} \cdot \mathbf{G}\right) \cdot \dot{\mathbf{q}}(t)+\mathbf{K} \cdot \mathbf{q}(t)=\mathbf{f}_{E}(t)+\mathbf{f}_{B}\left(\mathbf{q}, \dot{\mathbf{q}}, \omega_{0}, t\right),
$$

where $\mathbf{M}$ is the shaft mass matrix, $\mathbf{B}$ is the damping matrix, $\omega_{0} \cdot \mathbf{G}$ represents gyroscopic effects, $\mathbf{K}$ is the shaft stiffness matrix, $\mathbf{f}_{E}$ is the general vector of external forces and $\mathbf{f}_{B}$ is the vector representing bearing forces. Equation (1) is derived in the configuration space defined by the vector of generalized coordinates $\mathbf{q}(t)$. General solution of Equation (1) can be obtained by means of a numerical time integration assuming that the bearing forces are recalculated in each step of the integration.

Hydrodynamic forces $F_{H y}$ and $F_{H z}$ acting on the rotor in vertical and horizontal directions can be expressed as integrals of oil pressure $p=p(X, Z, t)$ (Polach et al., 2017b) in the form

$$
F_{H y}=-\int_{-\frac{L}{2}}^{\frac{L}{2}} \int_{0}^{2 \cdot \pi \cdot R} p(X, Z, t) \cdot \sin \frac{X}{R} \cdot \mathrm{d} X \mathrm{~d} Z, \quad F_{H z}=-\int_{-\frac{L}{2}}^{\frac{L}{2}} \int_{0}^{2 \cdot \pi \cdot R} p(X, Z, t) \cdot \cos \frac{X}{R} \cdot \mathrm{d} X \mathrm{~d} Z,
$$

where $R$ is the bearing radius, $L$ is the bearing length and $X$ and $Z$ are the circumferential and the axial coordinates, respectively, in a coordinate frame fixed to a bearing shell, where the origin of circumferential coordinate $X$ is located on the upper point of the shell.

Pressure field $p=p(X, Z, t)$ is described by the Reynolds equation. This equation can be found in the relevant literature in many forms respecting various considerations. Stachowiak and Batchelor (2014) derive the Reynolds equation in the form

$$
\frac{\partial}{\partial X}\left(\frac{h^{3}}{\eta} \cdot \frac{\partial p}{\partial X}\right)+\frac{\partial}{\partial Z}\left(\frac{h^{3}}{\eta} \cdot \frac{\partial p}{\partial Z}\right)=6 \cdot \frac{\partial\left[h \cdot\left(u_{1}+u_{2}\right)\right]}{\partial X}+12 \cdot \frac{\partial h}{\partial t},
$$

which is valid for thin films of constant density and under conditions of laminar flow, where $h=h(X, Z, t)$ is the height of the oil film, $\eta$ is the dynamic viscosity of oil and $u_{1}, u_{2}$ are circumferential bearing and journal velocities, respectively. A direct solution of Equation (3) yields areas of the film with negative pressure. In these areas the cavitation effect takes place and hydrodynamic pressure is approximately equal to the pressure in emerging vapour cavities. The hydrodynamic pressure has to be replaced by the pressure in the cavitated areas before Equation (2) is evaluated.

\section{Test rig for investigation of fluid-induced instabilities}

The rotordynamic characteristics as well as the fluid film behaviour will be experimentally investigated using the test rig whose scheme is shown in Fig. 1. The test rig is modular and shafts of different lengths and bearings of various lengths and clearances can be mounted into the bearing housings. The third bearing unit, which accommodates a loading cylinder, can be optionally installed. All bearings are supplied with a lubricant whose inlet pressure, flow and temperature are controllable. The shaft is driven by a $4 \mathrm{~kW}$ electric 


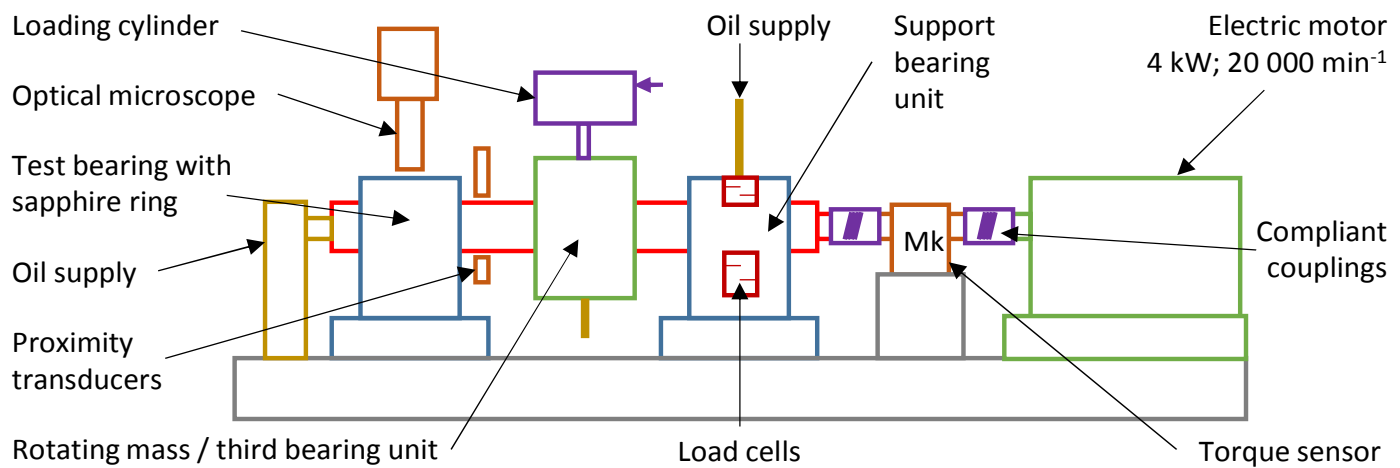

Fig. 1: Scheme of the rotor-bearing test rig.

motor, which can work at speeds up to 20,000 RPM. The motor is coupled to the shaft with a bellows coupling with rotational stiffness $900 \mathrm{~N} \cdot \mathrm{m} \cdot \mathrm{rad}^{-1}$ and lateral stiffness $320 \mathrm{kN} \cdot \mathrm{m}^{-1}$.

The proposed configuration of the test rig can serve for the investigation of both oil whirl and oil whip instabilities. The shaft in this configuration is rather slender and a massive disc is attached to the shaft at position that is shown in Fig. 2. Parameters of the bearings are summarized in Tab. 1. Lubricant (of the RENOLIN VG 46 type) is supplied to the bearings through $5 \mathrm{~mm}$ holes, which are located in the lower half of the bearing shells.

Tab. 1: Parameters of the used journal bearings.

\begin{tabular}{lccclcccc}
\hline Parameter & Symbol & Unit & Value & Parameter & Symbol & Unit & Value \\
\hline bearing diameter & $D$ & $(\mathrm{~mm})$ & 38.0 & $\begin{array}{l}\text { lubricant dynamic } \\
\text { viscosity }\end{array}$ & $\mu$ & $(\mathrm{mPa} \cdot \mathrm{s})$ & 28.3 \\
\hline bearing length & $L$ & $(\mathrm{~mm})$ & 20.0 & ambient pressure & $p_{a}$ & $($ bar $)$ & 1.0 \\
\hline radial clearance & $c_{r}$ & $(\mu \mathrm{m})$ & 40.5 & cavitation pressure & $p_{c}$ & $($ bar $)$ & 0.98 \\
\hline $\begin{array}{l}\text { lubricant } \\
\text { temperature }\end{array}$ & $t_{l u b}$ & $\left({ }^{\circ} \mathrm{C}\right)$ & 50.0 & $\begin{array}{l}\text { lubricant supply } \\
\text { pressure }\end{array}$ & $p_{s}$ & $($ bar $)$ & 1.25 \\
\hline
\end{tabular}

The simulations suggest (Fig. 3b) that the oil whip develops at 100-106 Hz (6,000-6,350 RPM) with a dominant response at $50-52 \mathrm{~Hz}$, which corresponds with the first bending mode. Further simulations suggest that the threshold speed for the oil whip is only little sensitive to the radial clearance or the lubricant dynamic viscosity. Furthermore, there is a short speed interval in which the oil whirl takes place $(92-98 \mathrm{~Hz})$. Although the proposed geometry is suitable for the investigation of both oil whirl and whip, a prolonged operation under the oil whip conditions is impossible because of a high level of vibrations of the disc. The vibrations exceed $1 \mathrm{~mm}$ peak-to-peak (Fig. 3a).

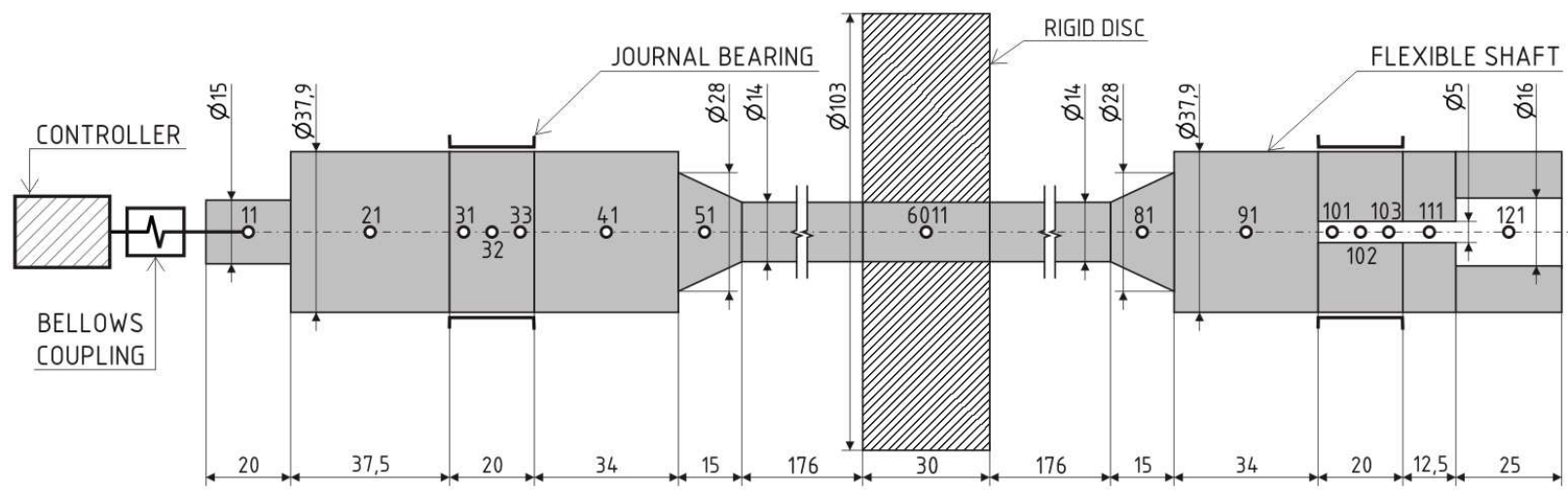

Fig. 2: Geometry and discretization of the shaft. 

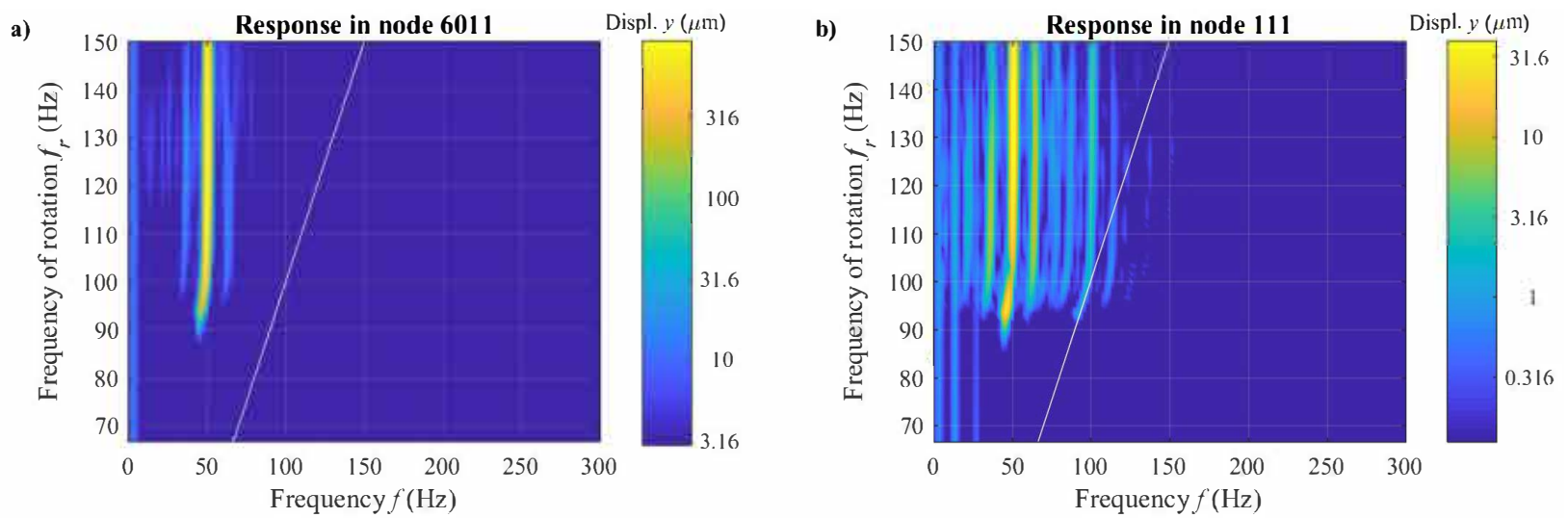

Fig. 3: Simulated response of the rigid disc (a) and of the journal in the bearing at the non-drive end (b).

\section{Conclusions}

This paper provided a basic overview of the state-of-the-art experimental and theoretical works that deal with the fluid-induced instability in the journal bearings. The general model that can be used for the simulations of rotating systems subjected to the oil-induced instabilities was also discussed.

Furthermore, the test rig that can be used in order to study the rotor dynamics and the tribological properties of oil films was introduced and its dynamic response was discussed. The proposed rig can be used for studying both the oil whirl and the oil whip and its modular character allows to mount various shafts and bearings.

\section{Acknowledgement}

The work has been supported by the project of the Czech Science Foundation No. 17-15915S "Nonlinear dynamics of rotating systems considering fluid film instabilities with the emphasis on local effects".

Simulations were performed using the AVL Excite software, which is available in the framework of the University Partnership Program of AVL List GmbH and its usage is greatly acknowledged.

\section{References}

Amamou, A. and Chouchane, M. (2014) Nonlinear stability analysis of long hydrodynamic journal bearings using numerical continuation. Mechanism and Machine Theory, 72, pp. 17-24.

Boyaci, A., Seeman, W. and Proppe, C. (2010) Stability and bifurcations of rotors in fluid film bearings. Proceedings in Applied Mathematics and Mechanics, 10, 1, pp. 235-236.

Byrtus, M., Hajžman, M. and Zeman, V. (2010) Dynamika rotujících soustav. University of West Bohemia, Plzeň. (in Czech)

De Castro, H. F., Cavalca, K. L. and Nordmann, R. (2008) Whirl and whip instabilities in rotor-bearing system considering a nonlinear force model. Journal of Sound and Vibration, 317, 1-2, pp. 273-293.

Fan, C.-C., Syu, J.-W., Pan, M.-C. and Tsao, W.-C. (2011) Study of start-up vibration response for oil whirl, oil whip and dry whip. Mechanical Systems and Signal Processing, 25, 8, pp. 3102-3115.

Glavatskikh, S. B. and Larsson, R. (2000) Oil film thickness measurement by means of an optic lever technique. Lubrication Science, 13, 1, pp. 23-35.

Lin, Q., Wei, Z., Wang, N., Ma, S. and Chen, W. (2015) Visualisation study on flow field of bearing lubrication. Lubrication Science, 27, 2, pp. 127-134.

Nakayama, K., Morio, I., Katagiri, T. and Okamoto, Y. (2003) A Study for Measurement of Oil Film Thickness on Engine Bearing by using Laser Induced Fluorescence (LIF) Method. SAE Technical Paper, 2003-01-0243.

Polach, P., Hajžman, M., Byrtus, M., Dyk, Š. and Smolík, L. (2017a) Mathematical Modelling of Rotor Systems with Journal Bearings in Limit Cases, In: Engineering Mechanics 2017 (ed. Fuis, V.), Brno University of Technology, Brno, pp. 794-797.

Polach, P., Smolík, L., Rendl, J. and Hajžman, M. (2017b) Influence of plain journal bearing parameters on the rotor nonlinear behaviour, in Proc. 14th Conf. on Dynamical Systems - Theory and Applications, Engineering Dynamics and Life Sciences (eds. Awrejcewicz, J., Kaźmierczak, M., Mrozowski, J. and Olejnik, P.), Łódź University of Technology, Faculty of Mechanical Engineering, Łódź, pp. 441-450.

Robbersmyr, K .G., Olsen, H., Karimi, H. R. and Tonder, K. (2014) Oil whip-induced wear in journal bearings. The International Journal of Advanced Manufacturing Technology, 73, 5, pp. 973-980.

Stachowiak, G.W. and Batchelor, A.W. (2014) Engineering Tribology. 4th ed. Butterworth-Heinemann, St. Louis. 